\title{
Peregrinação, experiência e sentidos: Uma leitura de narrativas sobre 0 Caminho de Santiago de Compostela ${ }^{1}$
} Míriam Cristina Carlos Silva e Tarcyanie Cajueiro Santos

\section{Resumo}

Objetiva-se refletir sobre as possibilidades

comunicacionais a partir da experiência da

peregrinação, registrada nas narrativas do site da

Associação de Confrades e Amigos do Caminho de

Santiago de Compostela; assim como investigar 0

modo como se narram estas experiências, discutindo-

se a produção de sentidos a partir do que é narrado.

Pergunta-se: 0 que dizem estas narrativas? Qual é a

importância delas para a experiência da peregrinação?

Estas narrativas propiciam pistas sobre 0 mundo contemporâneo, a experiência da peregrinação, a natureza do narrador, os enredos mais narrados e suas tramas, 0 leitor ideal esperado e 0 que se pretende comunicar ao narrar este tipo de experiência.

\section{Palavras-Chave}

Narrativas. Peregrinação. Santiago de Compostela.

\section{Míriam Cristina Carlos Silva}

I miriam.silva@prof.uniso.br

Doutora em Comunicação e Semiótica pela PUC-SP. Pós-doutora em Comunicação Social pela PUC-RS. Professora titular do Mestrado em Comunicação e Cultura da Universidade de Sorocaba - UNISO.

Tarcyanie Cajueiro Santos I tarcyanie@terra.com.br Pós-doutora e doutora em Ciências da Comunicação pela ECA/USP. Professora do Mestrado em Comunicação e Cultura da Universidade de Sorocaba - UNISO.

\section{Introdução}

As narrativas produzem parte da cultura, assim como são produtos culturais, já que materializam singularidades perceptivas acerca dos fenômenos experimentados pelo homem, na relação com o seu meio e com o seu imaginário. Possuem um importante papel de mediação, sobretudo à medida que ajudam a identificar, selecionar e interpretar os fatos, além de serem uma possibilidade para organizar, analisar, criticar, subverter, transformar e até substituir a experiência concreta, a partir da simulação, do jogo, da fabulação. Narrador, espaço, personagens e tempo intrincam-se e relacionam-se com a finalidade de produzir sentido e memória.

Narra-se em suportes e linguagens distintos, que vão desde as inscrições rupestres, passando pelas narrativas orais, nas quais a necessidade dos corpos presentes, tanto o do narrador quanto os dos ouvintes, concedia ao narrar um caráter ritualístico e essencialmente comunitário, vinculado à experiência do estar juntos no aqui e no agora, compartilhando o mesmo tempo e o mesmo espaço. 
Benjamin (1982) descreve dois tipos de narradores, o tradicional, que conhece em profundidade os fatos e as histórias locais, por nunca ter deixado a sua comunidade; e 0 viajante, aquele que vem de terras distantes e traz novas experiências. Ambos possuem uma relação vivencial direta com o fato a ser narrado, porém, o narrador tradicional está ligado a uma extensão ampla de tempo, pois percorreu períodos distintos de um espaço restrito para acumular o seu saber, enquanto que 0 narrador viajante se relaciona com uma maior amplitude de espaço, já que percorreu grandes distâncias, entre as quais dividiu distintas parcelas de tempo, a fim de guardar 0 seu conhecimento. 0 que ocorre, portanto, é que a narrativa se faz possível pela vivência e pelo acúmulo da experiência através do tempo ou através do espaço.

Diferentemente das comunidades orais, nas sociedades da escrita, possibilita-se um narrador de corpo ausente e a sobrevida das histórias narradas. Já na era do compartilhamento e da reprodução frenética de posts, nas contemporâneas redes sociais digitais, 0 narrar pode se converter em imediatismo, instantaneidade e fugacidade, expressas por curtidas e comentários empreendidos por indivíduos isolados e em constante estado de alerta. A memória não se produz apenas a partir dos acontecimentos presenciados, mas, também, da soma de signos ofertados pelas mídias.
Desta forma, a subjetividade se expõe potencialmente mais volátil, nômade, mutante e múltipla, assim como as identidades e os vínculos. Para Guattari (1993), a subjetividade humana é afetada nuclearmente pelas máquinas tecnológicas de informação e de comunicação, tanto no que tange às memórias e à inteligência quanto nos aspectos referentes à sensibilidade, aos afetos e até mesmo em relação aos fantasmas inconscientes.

Não cabe aqui polarizar a interferência das novas práticas comunicacionais, regidas pela tecnologia digital. 0 que se pretende discutir são as possibilidades comunicacionais a partir da experiência da peregrinação, retratada nas narrativas publicadas no site da Associação de Confrades e Amigos do Caminho de Santiago de Compostela no Brasil. Parte destas narrativas ocupa as redes sociais, fomentada pelo uso das novas tecnologias da comunicação. Pinho (2008) discute a necessidade de se superar os antagonismos analíticos que ora entendem a tecnologia como redentora, ora como vilã. Porém, afirma que é imperativo não se inocentar a tecnologia, tachando-a como neutra e colocando-a como mera ferramenta, e adverte sobre a necessidade de se investigar os processos que a envolvem em sua complexidade:

0 caos é gerador de diversidade na medida em que ele explode e vai criando novas ordens, mundos novos, associações e trocas inusitadas. 
É dinâmico, processual, não se deixa aprisionar. A subjetividade humana, assim como a natureza, também não é linear; é por demais complexa e processual, não permitindo reduzir-se ou limitar-se pela jaula de ferro dos cientificismos; pelo contrário, deve ser entendida na sua dimensão de criatividade e contínuo reordenamento. $\mathrm{E}$ as tecnologias não se situam fora da subjetividade humana (PINHO, p. 8, 2008).

Nas redes sociais digitais, as narrativas sobre peregrinação se multiplicam e são acessadas tanto por aqueles que já experimentaram a prática de peregrinar quanto pelos que desejam obter informações sobre rotas, o que levar, o que esperar, por vontade de se lançar na aventura ou simplesmente por curiosidade.

0 Caminho de Santiago de Compostela, uma das rotas mais tradicionais da religião católica, tornou-se um dos principais centros de peregrinação dos brasileiros no exterior, sendo recriada em diversas cidades brasileiras. Trombini (2013), ao pesquisar nas fontes de informações de várias oficinas localizadas no Brasil, constatou que o número de brasileiros que solicitaram e receberam a credencial ou passaporte até 2012 era de 22.291. Este número é próximo ao de Sandra Carneiro (2012), ao afirmar que mais de vinte mil brasileiros fizeram essa peregrinação (uma ou mais vezes) nos últimos quinze anos. Ainda segundo esta pesquisadora, 0 Brasil foi o terceiro país estrangeiro que contou com o maior número de peregrinos que recebeu a Compostela, em 2001. A credencial de peregrinos é uma precondição para receber a Compostela, sendo um documento gratuito que as organizações de acolhida fornecem às pessoas que a solicitam, como um meio de serem facilmente reconhecidos como peregrinos e de receber a hospitalidade do Caminho. Apenas podem solicitar a credencial os peregrinos que vão a pé, de bicicleta ou a cavalo, e cumprem as condições para poder recebê-la. A compostela, por sua vez, é um documento tradicional que comprova a peregrinação à Compostela, devotionis causa, mediante a apresentação da credencial, e desde que tenham cumprido todas as condições que são exigidas pela Catedral de Santiago.

De acordo com Carneiro (2001), diferentemente de outras peregrinações europeias, como a de Fátima em Portugal ou a de Lourdes na França, que são centradas na Virgem Maria, este caminho ultrapassa as fronteiras do catolicismo, constituindo-se como uma nova forma de peregrinação. "A ênfase na viagem e, como se alcança a igreja (a pé, de bicicleta ou a cavalo) marca a diferença, assumindo um significado especial. A longa jornada tem duplo aspecto físico e espiritual."

É neste contexto que se situa o objeto deste trabalho, as narrativas produzidas a partir de experiências relacionadas à peregrinação. São narrativas de um universo contemporâneo, conectado e globalizado. 0 que se busca aqui investigar é o modo como se narram estas experiências, discutindo-se as possibilidades de produção de sentidos a partir daquilo que é narrado. Entende-se que, a partir de uma 
leitura destas narrativas, pode-se obter pistas sobre o mundo contemporâneo e a experiência da peregrinação, também sobre a natureza do narrador, os enredos mais frequentemente narrados e suas tramas, bem como o leitor ideal esperado e 0 que se pretende comunicar ao narrar a experiência da peregrinação.

\section{$2 \mathrm{~A}$ peregrinação}

A peregrinação é um fenômeno milenar complexo e variado, que agrega histórica e culturalmente diversas práticas. Há muitos séculos, milhares de pessoas se deslocam de seus locais de origem, empreendendo principalmente a pé, mas também a cavalo ou de bicicleta, um percurso cuja finalidade originalmente estava atrelada à religiosidade: 0 cumprimento de uma pena, 0 pagamento de uma promessa, 0 agradecimento por uma graça alcançada, a evangelização para converter novos fiéis.

A peregrinação, enquanto uma jornada física e espiritual, ultrapassa 0 âmbito do catolicismo, estando presente em diversas culturas e religiões. Há nela uma busca que pressupõe um deslocamento e um ritual, por devoção e culto, evocando uma viagem a um local desconhecido ou estrangeiro, considerado sagrado.

Em sua raiz etimológica, peregrinação se relaciona com o aparecimento do outro; 0 estrangeiro que sai em busca de algo e vivencia momentos cujo desfecho é a transformação de si.
Steil (2003, p.30) alude a esse duplo movimento.

Em suas palavras:

Como se pode observar, se, por um lado, a peregrinação se exprime na história como um exercício de encontro com o 'outro', o estrangeiro, por outro, aponta para uma busca mística de si, como uma jornada de santificação que encontra seu ponto de chegada no reconhecimento de uma divindade que se manifesta no interior de cada devoto.

Steil (2003), seguindo a corrente interpretativa dos estudos antropológicos sobre peregrinação, adverte acerca das diferenças entre elas nesta área, e se opõe à visão clássica que estuda as peregrinações como sendo reflexo de um sistema de representações sociais único e coerente. As peregrinações, segundo este autor, agregam uma pluralidade de discursos e visões de mundo que direcionam e preenchem os seus rituais, combinando pessoas, textos e lugares. 0 que pode haver em comum entre os diversos rituais de peregrinação diz respeito às formas pelas quais as "pessoas", os "textos" e os "lugares" são vivenciados nesses eventos. Ou seja, as peregrinações são compostas de pessoas, lugares e textos escritos ou mitos orais sagrados, os quais dão poder de autoridade a esses eventos. 0 modo como as relações entre eles ocorre pode servir para a análise comparativa entre diferentes tipos de peregrinação, na medida em que levanta questões importantes sobre as mesmas:

Na sua expressão empírica, esses elementos - "pessoa", "lugar" e "texto" - coincidem nos eventos de peregrinação que se apresentam 
como depositários de tradições míticas e históricas atualizadas por seus peregrinos e demais agentes religiosos mediante a invocação de suas crenças, a veneração de suas imagens e a performance de seus rituais. Cada peregrinação, no entanto, pode enfatizar um ou mais desses elementos (STEIL, 2003, p.47).

Ao nos depararmos com 0 fenômeno das peregrinações nas sociedades contemporâneas ocidentais, especialmente as do Caminho de Santiago de Compostela, percebemos, nessa perspectiva, características que lhes são particulares e que permitem questionar conceitos clássicos relacionados ao domínio da religião, como é o caso do sagrado. Uma outra vivência do sagrado nas formas de religiosidade contemporâneas coexiste com valores e práticas seculares, modernas e pós-modernas. A noção ocidental de religião, baseada em uma relação transcendente com Deus, cede espaço para uma concepção imanente, mais próxima às religiões orientais.

Hoje, a motivação parece também se desvincular do propósito religioso das primeiras peregrinações, para se desdobrar na busca por aventura, atividade física, turismo, transformação interior ou apenas para a suspensão do cotidiano, como um modo de romper a monotonia.

A "segregação da experiência" (GIDDENS, 2002), com a expansão da técnica e dos "não lugares" (AUGÉ, 1994), cria um ambiente asséptico que, frequentemente, é desafiado e burlado por aqueles que buscam dar sentido às suas vidas. A estetização do cotidiano não se opõe à sua sacralização. 0s "não lugares", locais de passagem que podem ser pensados como os shopping centers, os aeroportos e o turismo podem ser ressignificados e se tornarem locais identitários, com sentidos. 0 fenômeno da peregrinação nas sociedades contemporâneas ocidentais pode representar um outro modo de se vivenciar 0 sagrado, na medida em que traz consigo elementos seculares, que inspiram as experiências religiosas. 0 Caminho de Santiago de Compostela, nesta perspectiva, mesmo atravessado pelo movimento do turismo, pela busca da relação com a natureza, pela prática de exercícios físicos e do corpo saudável, ainda assim traz consigo a experiência dos sentidos.

Autores que pesquisam 0 aumento das peregrinações na sociedade contemporânea, especialmente a intensa procura pelo Caminho de Santiago de Compostela e a construção de novas rotas de peregrinação no Brasil, chamam a atenção para a autonomia da experiência do sagrado em relação às instituições religiosas tradicionais. Pesquisadores como Steil e Carneiro (2008, p.113) apontam para a reinvenção das peregrinações, na medida em que "os sujeitos religiosos incorporam o turismo como mediação da experiência do sagrado, que absorve elementos de lazer, de consumo e de marketing". Enquanto os peregrinos de outrora objetivavam a transcendência, utilizando seus corpos como instrumentos de penitência e perdão a um Deus além deste mundo, os peregrinos contemporâneos fazem a jornada no intuito de encontrar 0 
Deus que está neles mesmos. A peregrinação, nesse sentido, torna-se uma experiência interior. "Nesses contextos, as experiências dos sujeitos são os próprios princípios geradores de autenticidade da relação que se estabelece com o sagrado" (STEIL \& TONIOL, 2010). Nas novas peregrinações, os corpos dos peregrinos e da natureza aparecem como lugares privilegiados de contato entre 0 eu e Deus. Os peregrinos as veem como uma possibilidade de aperfeiçoamento pessoal e transformação de si. Além disso, a nova modalidade de peregrinação aparece não somente como manifestação de uma experiência religiosa, mas também como expressão cultural (turística).

Estudiosos da peregrinação a percebem como um sistema abrangente de trocas políticas e econômicas, no qual "competem simultaneamente discursos religiosos e seculares, ortodoxias oficiais e interpretações populares de um mesmo código doutrinário, grupos religiosos estabelecidos e seitas proféticas de contestação ao status quo" (STEIL, 2003, p.45). As novas peregrinações, assim, são compostas de interesses turísticos, místicos, culturais, históricos e ecológicos, que não se excluem, combinando-se em um contexto social amplo, cujas fronteiras tornam-se porosas (STEIL E CARNEIRO, 2008). E não se pode descartar que essa porosidade comporte, também, uma forma de comunicação, um "acontecimento comunicacional", frequentemente relatado nas narrativas relacionadas à peregrinação. Nela, a suspensão do cotidiano, um outro modo de vivenciar o tempo, em um espaço estranho, enseja a promessa de encontros e trocas efetivas, do peregrino consigo, com os outros, com a natureza e com o sagrado, nomeado como Deus, 0 Inexplicável, o Intangível, o Todo-Poderoso, entre outros termos.

\section{Peregrinar e Narrar}

As Redes Sociais exercem distintas funções relacionadas à peregrinação, sobretudo a partir da veiculação de narrativas sobre 0 tema. Elas parecem colaborar para 0 surgimento e disseminação de peregrinações e novas modalidades de peregrinos que, cada vez mais, precisam do mercado para se realizar. Entre um grande número de entidades, escolhemos a Associação de Confrades e Amigos do Caminho de Santiago de Compostela, fundada em 25 de novembro de 1995 , tendo mais de 2.000 associados, segundo informação do site. 0 nome dessa rede social propõe uma associação (organização de pessoas para um fim ou interesse comum), formada por confrades (companheiro, colega, camarada, sócio, cada um dos membros de uma sociedade religiosa, etc) e amigos (que tanto pode significar aquele que tem gosto por alguma coisa, do latim amicu, quanto ter o sentido do indivíduo ligado a outro por amizade). 0 interesse comum que associa aqueles que participam do site é o Caminho de Santiago de Compostela.

Trata-se de uma das muitas associações existentes no mundo, destinadas a promover e apoiar as peregrinações pelo Caminho de 
Santiago de Compostela, na Espanha. Como outras entidades, ela busca promover "eventos nas áreas social, cultural, de esporte e de turismo, tendo como principal objetivo incentivar, apoiar, auxiliar, informar e preparar as pessoas, futuros Peregrinos, a percorrerem em Peregrinação 0 Caminho de Santiago de Compostela". Entre suas atribuições, resumidamente, ela emite a "credencial oficial do peregrino", documento que permite ao peregrino utilizar os albergues existentes ao longo do percurso; divulga os caminhos no Brasil; promove palestras e caminhadas preparatórias; vende livros e guias sobre o caminho; realiza plantão uma vez por mês com peregrinos que já fizeram o caminho para passar a sua experiência; $\mathrm{e}$ promove confraternização em almoços, jantares ou encontros agendados.

\section{0 site da Associação apresenta várias} informações sobre 0 Caminho de Santiago de Compostela. Entre elas: a sua história; o que é o caminho; a catedral; a preparação; a necessidade de 0 peregrino ter uma credencial para poder dormir nos albergues. Há também dicas sobre as caminhadas diárias; 0 que levar; como se preparar fisicamente; conselhos práticos; alusão às melhores épocas para peregrinar; preparação física; os albergues ao longo do caminho; as despesas; os equipamentos necessários; a ética do peregrino. 0 site ainda apresenta as dez principais razões para se percorrer $800 \mathrm{~km}$ a pé, rumo à Catedral de Santiago de Compostela, onde, supostamente, estão guardados os restos mortais de um dos doze apóstolos de Jesus, Tiago Maior: "encontrar-se consigo mesmo; buscar o sentido da vida; procurar um ambiente propício para se pensar e refletir; cumprir uma promessa; estar em contato com outras pessoas; seguir as indicações que outros foram deixando ao longo dos séculos; apreciar os monumentos históricos e conhecer as lendas do Caminho; aprofundar um conhecimento cultural sobre a arte do Caminho; renovar a fé de um Apóstolo de Jesus". No entanto, não há, de acordo com 0 site, 0 certo ou o errado, pois o motivo que leva à peregrinação é pessoal, ou seja, "aquele que é verdadeiro para você". Desta forma, "a intenção ou a verdadeira motivação é o que confere a condição de peregrino, segundo as reflexões de Santo Agostinho: 'É a intenção que dá valor às ações humanas"”. Ressalta-se, também, que não há, necessariamente, um motivo para se realizar a caminhada, que basta atender ao chamado, e que, durante a caminhada, as razões surgirão. Este "chamado", subjetivo, inexplicável, indefinido, é mais um dos elementos recorrentes nas narrativas sobre a peregrinação. Sugere-se que aquele que sente 0 desejo de realizar a peregrinação atende a um chamado, talvez místico, ou tão somente subjetivo e pessoal - um desejo de encontrar algo além do cotidiano, com vistas a uma transformação interior, a qual se refletirá exteriormente.

A Associação considera que 0 primeiro passo para se tornar um peregrino é ambientar-se com a rota; e, para isso, disponibiliza a "História do Caminho e das peregrinações". Além disso, conforme 0 site, o contato com a experiência de outros peregrinos também pode ajudar bastante. Há sugestão de 
diversos livros sobre quem fez a peregrinação, assim como depoimentos e histórias de vários peregrinos sobre o "seu caminho". As narrativas são, portanto, para muitos, a primeira forma de contato com 0 caminho, que se inicia a partir da leitura da experiência relatada pelos narradores-viajantes, não necessariamente a partir da própria experiência.

Desta forma, a Associação expõe em seu site, no link "Meu caminho", narrativas enviadas por peregrinos que desejam compartilhar a sua experiência.

Uma narrativa, convencionalmente, consiste em um texto contendo narrador, tempo, espaço, personagens e um enredo, sendo fundamentada na transformação dos fatos pela ação do tempo. É comum em muitos dos relatos do site o uso da primeira pessoa, o que reforça a presença da função emotiva da linguagem, centrada no emissor e em sua experiência, ou seja, o narrador é também personagem daquilo que narra, de modo que se pode remeter ao narrador viajante de Benjamin: alguém que tem o que contar, porque experimentou a cultura de terras distantes.

A experiência é demonstrada como subjetiva, pessoal e única, o que reforça a ideia de que, por mais que os interessados leiam os relatos, é fundamental fazer o caminho, viver a própria experiência. Isso fica patente, a começar pelo título, no relato de Zélia Maria Ferreira²: "Minhas ${ }^{3}$ impressões sobre o Caminho de
Santiago". A peregrina conta que fez 0 caminho pela terceira vez, com a diferença de estar acompanhada, na terceira. Não há menção a grandes dificuldades ou problemas, mas se enfatiza a superação: "Alguns dias a caminhada ultrapassou o que era esperado. Teve um dia de 37 e outro de 38 $\mathrm{km}$. Marca recorde, para mim, uma peregrina que das outras vezes se valeu de caronas ou de ônibus para suportar os últimos quilômetros do dia" - a força da palavra suportar sugere um certo sofrimento, não explícito, mas que deverá ou poderá ser percebido pelo leitor, quase como um conselho; a emoção:

A chegada à Catedral foi emocionante, revi os lugares já passados e me deu certo frenesi de me ver mais uma vez por ali, num lugar tão distante de casa e tão familiar. Na missa, chorei por me emocionar ao ver o botafumeiro $\mathrm{e}$ a freira cantando o Hino a Santiago, num tom envolvente e inebriante que preenche a alma de vida. Vida esta conquistada através de esforço e muita saúde durante 0 Caminho.

Aqui, misturam-se elementos relacionados à

experiência física e à alma; e vem a transformação:

Para mim, algumas mudanças se apresentaram, a visão de que a vida é finita e que preciso aproveitar cada minuto que segue com todo o saber $\mathrm{e}$ atitude. Outra parte que me fez mudar depois do Caminho é que as emoções são para serem sentidas e vividas e me sinto mais livre para senti-las sem nenhuma crítica, a qualquer hora.

No relato de Monica Mouri, a função emotiva da linguagem também é privilegiada, a começar 
pelo título: "Meu Caminho" 5 , que repete o nome do link. Nesta narrativa, mais uma vez, a ênfase recai sobre a experiência subjetiva, individual e única, mas ressalta-se o compartilhamento do que foi vivido, durante o próprio percurso, pelas redes sociais digitais:

Durante este período fiz anotações e posts no Facebook, compartilhando um pouco da enorme emoção e encantamento com as experiências vivenciadas. Obtive um retorno além do esperado de pessoas que se emocionaram comigo, muitas delas não as conheço pessoalmente (....).

Neste sentido, o compartilhamento das

informações ao longo do percurso, em processo, simula as narrativas orais. Não há 0 dividir do mesmo espaço e tempo, tampouco os corpos interagem presencialmente, mas é possível ocorrer um maior imediatismo que, inclusive, parece converter a narrativa em espetáculo. 0 narrador assume um contrato com o leitor, entendendo que este realmente se emociona com os relatos, vivenciando o caminho à distância. 0 leitor converte-se também em narrador, e o narrador, em leitor, o que alimenta a narrativa. 0 compartilhamento pelas redes, entretanto, não descarta 0 encontro corpo a corpo, com o outro, durante o próprio caminho:

Fiz amigos, andamos juntos por dias, rimos, choramos, cantamos, comemoramos, nos perdemos, voltamos a nos encontrar. Essa dinâmica intensa de cruzar diariamente com pessoas de todas as idades, vindas dos quatro cantos do mundo, uma verdadeira torre de
Babel de línguas, cheiros e costumes nos dá a necessária noção do Todo.

Outro aspecto de relevo é o encontrar-se, sobretudo pela vivência solitária:

Muitas dessas experiências, imersões profundas e dolorosas desnudaram sentimentos há muito guardados. Esse encontro comigo mesma foi um dos pontos altos do meu caminho, era a minha proposta. Em muitos momentos e até por dias inteiros andei completamente só, por opção ou por circunstâncias.

Um único relato parece demonstrar que a

experiência de peregrinar dá vazão a possibilidades

distintas de interação, não sem a dor e 0

sofrimento, como se estes fossem o tributo a ser pago para se alcançar a transformação almejada.

Em "Homens que pedalam montanhas", de Alfredo A. Bechara, o breve relato descreve subjetivamente a viagem, iniciando-se, no título figurativo, com uma referência ao esforço físico descomunal para se realizar a jornada: "Há exato um ano tive a felicidade de fazer o Camiño Francês, de bike, em 13 dias. Foi uma viagem fantástica, intrínseca, cultural e produtiva". Note-se que, neste caso, os objetivos desvinculam-se da busca religiosa ou mística. Destacam-se os obstáculos, mostrando-se a atividade física como norteadora:

Como todo começo, o mais difícil foi logo de início, nos Pirineus, aonde tive que superar as cãibras e contraturas musculares, que terminaram 
no terceiro dia, quando fui de Villava-Pamplona até Estela, subindo o mítico Morro dos Perdões (aonde vi que conseguiria 0 objetivo) e atravessando a Ponte de La Reina.

A superação desses obstáculos e o papel auxiliar do próprio site: "Daí a viajem (sic) fluiu, com adaptação total, muito me ajudou a ACACS-SP, com os mapas, as dicas, conselhos e planejamento, que foi fundamental para o sucesso da viajem (sic)". Aparentemente, a superação física, associada à performance atlética, parece ser 0 objetivo maior da viagem, a meta a ser alcançada, não algo transcendente e de caráter interior, neste caso.

0 contato com a natureza, a beleza das paisagens percorridas são elementos que povoam a maior parte das narrativas sobre peregrinação, transformandoas em descrição, em tempo presente, 0 que converte o próprio caminho em protagonista e que pode ampliar a sensação, no leitor, de compartilhar o mesmo espaço construído pelo narrador. No relato de Cirene de Oliveira Colen de Almeida ${ }^{6}$, ela descreve: "Bem cedo um bilhão de estrelas e uma lua linda iluminando meu caminho, logo em seguida um nascer do sol fantástico, transformando o breu em um céu mais azul que meus olhos já viram" (...). Já Katia Tolomei Fonseca ${ }^{7}$ ressalta a importância de se produzir as narrativas enquanto se caminha: "Amo escrever e articular conhecimento, ideia, sentimento e pensamento (...)". Kátia também descreve a paisagem, mas expõe não apenas as suas belezas, como também seus obstáculos, concentrando protagonista e antagonista no próprio caminho, que oferece belezas e perigos:

(...) Vi montanhas e caminhei com mosquitos. Tive paisagens lindíssimas e que não imaginava que fossem existir ali. As flores me acompanharam por todos os montes. Eram roxas, amarelas, vermelhas e laranjas. 0 verde era tão forte na natureza que contrastava com 0 azul do céu... Marchei todo o tempo com muitos mosquitos ao meu redor e com dor nas bolhas em meus pés. A descida foi difícil entender que era tão dura de fazer. Senti cada passo de minha descida. As pedras atrapalham demais. Marcha solitária e doída. Ao escrever estas palavras me emociono, pois aqueles sentimentos foram fortes em mim. Marcha de descida que durou cinco horas com três interrupções para descanso, comida e energéticos. Neste dia fiquei mais forte (...).

A descrição não apenas dá ao leitor uma ideia das dificuldades que enfrentará aquele que se dispuser a viver o caminho, mas registra a atualização da experiência pela própria narradora, que afirma se emocionar ao escrever.

Angelo Lage ${ }^{8}$ escreve sobre transformação e sobre a importância de se relatar a experiência, a fim de compartilhá-la com outros:

Após a mágica e profunda experiência no Caminho de Santiago, eis que cheguei a minha casa e a minha família. Como vocês da ACACS-SP mesmo disseram preparado para uma Nova Vida. Literalmente espero dar início a uma nova etapa em minha vida, recuperando todo o tempo que perdi com coisas que não valem a pena... Es- 
tou repensando tudo e recatalogando cada etapa, cada escrito no meu caderno que agrupou cerca de 130 páginas de escritos... As experiências que lá vivi ficou (sic) gravadas em meu coração e em minha alma... Ainda estou degustando-as para enfim comungar de maneira sábia com todos... Afinal para que serve uma luz no candelabro se a colocamos embaixo da cama?

Talvez a experiência de realizar uma peregrinação não possa ser substituída por sua narrativa, pois o caminhar constrói uma história que se experimenta passo a passo, com vivências, interações, intenções e intensidades distintas para cada peregrino. Porém, as narrativas encontradas no site da Associação de Confrades e Amigos do Caminho de Santiago auxiliam, de forma fácil, prática e rápida, na construção de um repertório prévio que, em alguma medida, fornece conforto e segurança para aqueles que pretendem realizar a jornada. Há muito os peregrinos contam com as narrativas sobre peregrinação para auxiliarem 0 seu caminho, mas se outrora esse acesso se dava, sobretudo, pelos livros, com seus altos custos de produção e de aquisição, hoje, conta-se com uma miríade de informações, as quais correspondem à multiplicidade de motivos que levam o sujeito a aventurar-se como peregrino. Outra mudança é a de que os livros eram escritos por autoridades, especialmente religiosas, fornecendo uma voz oficial que alimentava a necessidade de informação. Com a presença das narrativas de peregrinação nas redes sociais, pelo baixo custo que representam $\mathrm{e}$ pela quase ausência de crítica e de censura, dá-se voz a um imenso número de sujeitos e, deste modo, evidencia-se a imensa gama de motivações, idades, personalidades, profissões dos peregrinos, o que pode vir a ser um elemento motivador para uma grande diversidade de leitores.

Ao entrar em contato com estas narrativas, ao repercuti-las e ao interagir com elas, antes mesmo de optar por realizar ou não a peregrinação, 0 leitor passa a ser um sujeito da comunicação ou em comunicação, como sinalizou França:

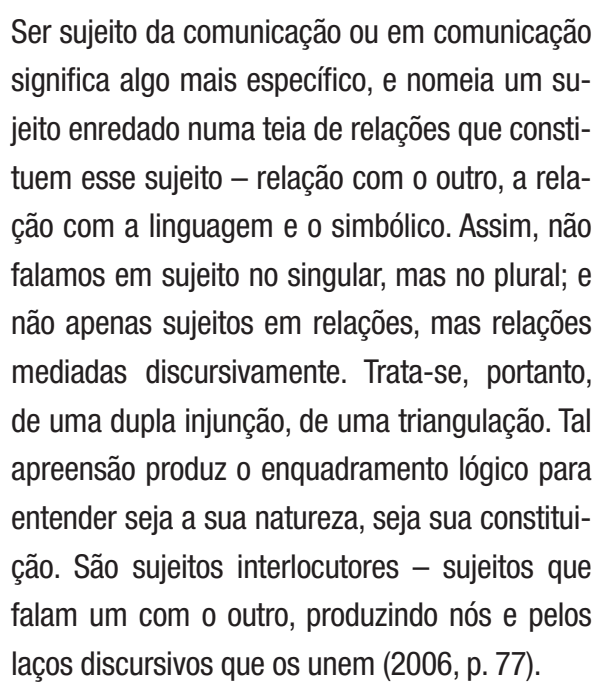

Ser sujeito da comunicação ou em comunicação significa algo mais específico, e nomeia um sujeito enredado numa teia de relações que constituem esse sujeito - relação com o outro, a relação com a linguagem e o simbólico. Assim, não falamos em sujeito no singular, mas no plural; e não apenas sujeitos em relações, mas relações mediadas discursivamente. Trata-se, portanto, de uma dupla injunção, de uma triangulação. Tal apreensão produz o enquadramento lógico para entender seja a sua natureza, seja sua constituição. São sujeitos interlocutores - sujeitos que falam um com o outro, produzindo nós e pelos laços discursivos que os unem (2006, p. 77).

Mesmo que opte por não realizar o Caminho, 0 leitor das narrativas sobre a peregrinação poderá trazer consigo a marca da vieira (concha usada pelos peregrinos, pendurada no pescoço, roupas, mochila ou cajado, com o significado de busca de conhecimento e proteção). Dela se apropriará, ainda que invisível, e também de seu discurso simbólico, para interagir com outros, a partir desta apropriação.

\section{Considerações Finais}

0 fenômeno da peregrinação na sociedade contemporânea apresenta ligações com as mídias 
digitais, colaborando para a disseminação de novas formas de se vivenciar o sagrado, em conjunto com a produção de novas subjetividades. As modalidades de peregrinação, como as do Caminho de Santiago de Compostela, aparecem como propiciadoras de uma experiência ligada ao projeto de autoconhecimento. As narrativas, por sua vez, não poderiam deixar de existir, apresentando-se como reafirmação e mobilização das transformações em si, propiciadas pela experimentação do caminhar, ou, talvez, por um acontecimento comunicacional, a partir do qual haverá uma mudança significativa, ainda que não definitiva, tal como as subjetividades, que se modificam conforme mudam os enredos e os atores com os quais se atua.

Nos relatos presentes no site da Associação de Confrades e Amigos do Caminho de Santiago de Compostela, a estrutura narrativa convencional permanece quase inalterada: há um narrador, enredo, tempo, espaço, personagens. A diferença proporcionada pelo suporte digital é que, como uma marca da contemporaneidade, são narrativas mais sintéticas, condensadas e até superficiais, 0 que atende à necessidade de agilidade, rapidez e leveza da atualidade. Acompanhadas de poucas imagens, fotografias de caráter ilustrativo, que reforçam elementos-chave apontados no texto, sem excesso de detalhes, estas micronarrativas limitam-se ao essencial, a exemplo da mochila levada pelo peregrino, que não deve pesar muito, mas trazer o suficiente e o necessário, apenas o que interessa ao narrador e 0 que ele pensa interessar a seus leitores. A trama quase sempre se inicia com o motivo que levou o peregrino à realização do caminho. Na sequência, começa a jornada, descrevem-se as belezas, as emoções positivas, os obstáculos superados. 0 desfecho se dá com a chegada emocionante à Catedral de Santiago de Compostela - tudo em três, quatro, cinco, no máximo oito parágrafos, não mais que doze ou quinze linhas. Variam os motivos e a intensidade com que se percebem os obstáculos: dificuldades com o clima, bolhas nos pés, fome, sono, saudades de casa e outras privações. São recorrentes as menções à natureza, à receptividade dos hospitaleiros, aos que se tornaram amigos ao longo do caminho. Muito embora, por vezes, o Caminho se torne 0 protagonista e até mesmo 0 antagonista, 0 centro da narrativa é o sujeito que narra, com suas impressões, seus motivos, sua vivência e sua busca por mudança - 0 centro é 0 eu.

Em que pesem as diferenças entre as narrativas apresentadas pelos peregrinos, quase todas falam de um antes e de um depois - uma transformação, que parece ser também o elemento que leva à própria narrativa, ao ato de narrar - ou seja, não basta sentir essa transformação, é necessário comunicá-la ao mundo, incentivar a outros que empreendam as suas jornadas e construam a sua própria narrativa rumo ao encontro com mais um entre os muitos "eus" de que se é composto - 0 sujeito andarilho, que gastará a sola de seus sapatos para ter o que contar.

Desta forma, as narrativas configuram-se como um registro da experiência de peregrinar, cujo 
objetivo final é ser ponte para o outro, em busca de compartilhamento, em um irmanar-se em um contrato que visa validar aquilo que foi vivido. Por isso, não necessariamente 0 leitor ideal seria aquele disposto a realizar a peregrinação, mas sim aquele disposto a acreditar que 0 Caminho proporcionou uma transformação da subjetividade. Compartilhando a narrativa, vivese mais uma vez a própria experiência, incitandose uma espécie de conversação. De qualquer modo, seja oral, escrita ou compartilhada pelas redes sociais, a narrativa segue, operando como ponte entre sujeitos que se confraternizam, fornecendo parte da realidade, criticando-a e criando outros mundos possíveis.

\section{Referências}

AUGÉ, Marc. Não lugares: introdução a uma antropologia da supermodernidade. Campinas: Papirus, 2012.

BENJAMIN, Walter. 0 narrador: Considerações sobre a obra de Nikolai Leskov. In: Magia, técnica, arte, política. São Paulo: Brasiliense, 1982.

CARNEIRO, Sandra de Sá. No Caminho de Santiago de Compostela: significados e passagens no itinerário comum europeu. Apresentado na IV REUNIÃO DE

ANTROPOLOGIA DO MERCOSUL - Curitiba, Paraná, Brasil, de 11 a 14 de novembro de 2001. Disponível em: http://www.caminhodesantiago.com.br/estudos/sandra. htm. Acesso em 14 de janeiro de 2015.

"As Peregrinações Como Atrações Turísticas". Espaço e Cultura, UERJ, RJ, n. 31, p.66-79, jan./jun., 2012. Disponível em: http://www.e-publicacoes.uerj.br/ index.php/espacoecultura/. Acesso em 12 de jun., 2013.
FRANÇA, Vera. Sujeito da comunicação, sujeitos em comunicação. In: GUIMARÃES, Cesar e FRANÇA, Vera. Na mídia, na rua: Narrativas do cotidiano. Belo Horizonte: Autêntica, 2006.

GIDDENS, Anthony. Modernidade e Identidade. Rio de Janeiro: Zahar, 2002.

\section{GUATTARI, Félix. Caosmose: Um novo paradigma} estético. Rio de Janeiro: 34 Letras, 1993.

PINHO, Júlio Sá de. As novas tecnologias da comunicação e informação diante da transversalidade entre natureza e cultura. Culturas Midiáticas - Ano I, n. 01 - jul./dez./2008 UFPb Disponível em http:// periodicos.ufpb.br/ojs/index.php/cm/article/view/11630 STEIL, Carlos Alberto. "Peregrinação, Romaria e Turismo religioso: raízes etimológicas e interpretações antropológicas". In: E. S. ABUMANSSUR. (org.).

Turismo religioso: ensaios antropológicos sobre religião e turismo. Campinas: Papirus, p.29-54, 2003.

STEIL, Carlos Alberto; CARNEIRO, Sandra de Sá. "Peregrinação, Turismo e Nova Era: caminhos de Santiago de Compostela no Brasil". Religião e Sociedade, Rio de Janeiro, 28(1): 105-124, 2008.

STEIL, Carlos Alberto; TONIOL, Rodrigo. Ecologia, nova era e peregrinação: uma etnografia da experiência de caminhadas na Associação dos Amigos do Caminho de Santiago de Compostela do Rio Grande do Sul. Debates do NER, Porto Alegre, UFRS, v. 11, n. 17, jan./jun., 2010. Disponível em: http://www.seer.ufrgs.br/debatesdoner/ article/view/17173/10100

TROMBINI. Valdinei. A narrativa dos peregrinos a Santiago de Compostela: uma análise comunicacional.

Dissertação de Programa de Pós-Graduação em Comunicação e Cultura da Universidade de Sorocaba. Sorocaba, SP, 2013. 


\section{Pilgrimage, experience and meaning: A reading of narratives about Santiago de Compostela Way}

\section{Abstract}

This work aims to reflect on the communication possibilities from the pilgrimage experience, recorded in narratives at the site of Santiago de Compostela Way Brotherhood and Friends Association. We intend to know how these experiences are narrated, discussing the production of sense from the narrative. What do these narratives say? What is their relevance for the experience of pilgrimage? Reading these stories provides clues about the contemporary world and the experience of the pilgrimage; on the nature of the narrator, on the plots more often narrated and their stories; as well as concerning the expected ideal reader and what we want to communicate by narrating the pilgrimage experience.

\section{Keywords}

Narratives; pilgrimage; Santiago de Compostela, Media culture.

\section{Peregrinaje, experiencia y sentido :} Una lectura de las narraciones sobre el Camino de Santiago de Compostela

\section{Resumen}

Objetivamos reflexionar sobre las posibilidades de comunicación de la experiencia de la peregrinación, registrada en las narraciones del sitio de los Hermanos y Amigos de la Santiago de Compostela. También investigamos cómo se narran estas experiências e la producción de significados de la lo que se narra. Preguntamos: ¿qué dicen estos relatos? ¿Cuál es la importancia de que la experiencia de la peregrinación en el mundo contemporáneo? Estas narraciones dan pistas sobre la experiencia de la peregrinación, la naturaleza del narrador, las parcelas más narrados, el lector ideal esperado y lo que quiere comunicar a narrar este tipo de experiencia.

\section{Palabras clave}

Narrativas. Peregrinación. Santiago de Compostela. 


\section{Expediente}

A revista E-Compós é a publicação científica em formato eletrônico da Associação Nacional dos Programas de Pós-Graduação em Comunicação (Compós). Lançada em 2004, tem como principal finalidade difundir a produção acadêmica de pesquisadores da área de Comunicação, inseridos em instituições do Brasil e do exterior.

\section{E-COMPÓS I www.e-compos.org.br I E-ISSN 1808-2599}

Revista da Associação Nacional dos Programas de Pós-Graduação em Comunicação. Brasília, v.18, n.2, maio/ago. 2015. A identificação das edições, a partir de 2008, passa a ser volume anual com três números. Indexada por Latindex I www.latindex.unam.mx

\section{CONSELHO EDITORIAL}

Alexandre Rocha da Silva, Universidade Federal do Rio Grande do Sul, Brasil Alexandre Farbiarz, Universidade Federal Fluminense, Brasil Ana Carolina Damboriarena Escosteguy, Pontifícia Universidade Católica do Rio Grande do Sul, Brasil

Ana Carolina Rocha Pessôa Temer, Universidade Federal de Goiás, Brasil Ana Regina Barros Rego Leal, Universidade Federal do Piauí, Brasil André Luiz Martins Lemos, Universidade Federal da Bahia, Brasil Andrea França, Pontifícia Universidade Católica do Rio de Janeiro, Brasil Antonio Carlos Hohlfeldt, Pontifícia Universidade Católica do Rio Grande do Sul, Brasil

Arthur Ituassu, Pontifícia Universidade Católica do Rio de Janeiro, Brasil Álvaro Larangeira, Universidade Tuiuti do Paraná, Brasil Ângela Freire Prysthon, Universidade Federal de Pernambuco, Brasil César Geraldo Guimarães, Universidade Federal de Minas Gerais, Brasil Cláudio Novaes Pinto Coelho, Faculdade Cásper Líbero, Brasil Daisi Irmgard Vogel, Universidade Federal de Santa Catarina, Brasil Daniela Zanetti, Universidade Federal do Espírito Santo, Brasil Denize Correa Araujo, Universidade Tuiuti do Paraná, Brasil Eduardo Antonio de Jesus, Pontifícia Universidade Católica de Minas Gerais, Brasil

Eduardo Vicente, Universidade de São Paulo, Brasil

Elizabeth Moraes Gonçalves, Universidade Metodista de São Paulo, Brasil Erick Felinto de Oliveira, Universidade do Estado do Rio de Janeiro, Brasil Francisco Elinaldo Teixeira, Universidade Estadual de Campinas, Brasil Francisco Paulo Jamil Almeida Marques, Universidade Federal do Ceará, Brasil Gabriela Reinaldo, Universidade Federal do Ceará, Brasil Gisela Grangeiro da Silva Castro, Escola Superior de Propaganda e Marketing, Brasil

Goiamérico Felício Carneiro Santos, Universidade Federal de Goiás, Brasil Gustavo Daudt Fischer, Unisinos, Brasil

Herom Vargas, Universidade Municipal de São Caetano do Sul, Brasil
Itania Maria Mota Gomes, Universidade Federal da Bahia, Brasil Janice Caiafa, Universidade Federal do Rio de Janeiro, Brasil Jiani Adriana Bonin, Universidade do Vale do Rio dos Sinos, Brasil José Afonso da Silva Junior, Universidade Federal de Pernambuco, Brasil José Luiz Aidar Prado, Pontifícia Universidade Católica de São Paulo, Brasil Kati Caetano, Universidade Tuiuti do Paraná, Brasil

Lilian Cristina Monteiro França, Universidade Federal de Sergipe, Brasil

Liziane Soares Guazina, Universidade de Brasília, Brasil Luíza Mônica Assis da Silva, Universidade de Caxias do Sul, Brasil Luciana Miranda Costa, Universidade Federal do Pará, Brasil Malena Segura Contrera, Universidade Paulista, Brasil Marcel Vieira Barreto Silva, Universidade Federal da Paraíba, Brasil Maria Ogécia Drigo, Universidade de Sorocaba, Brasil Maria Ataide Malcher, Universidade Federal do Pará, Brasil Maria Clotilde Perez Rodrigues, Universidade de São Paulo, Brasil Maria das Graças Pinto Coelho, Universidade Federal do Rio Grande do Norte, Brasil

Mauricio Ribeiro da Silva, Universidade Paulista, Brasil

Mauro de Souza Ventura, Universidade Estadual Paulista, Brasil

Márcio Souza Gonçalves, Universidade do Estado do Rio de Janeiro, Brasil Micael Maiolino Herschmann, Universidade Federal do Rio de Janeiro, Brasil Mirna Feitoza Pereira, Universidade Federal do Amazonas, Brasil Nísia Martins Rosario, Universidade Federal do Rio Grande do Sul, Brasil Potiguara Mendes Silveira Jr, Universidade Federal de Juiz de Fora, Brasil Regiane Ribeiro, Universidade Federal do Paraná, Brasil Rogério Ferraraz, Universidade Anhembi Morumbi, Brasil Rose Melo Rocha, Escola Superior de Propaganda e Marketing, Brasil Rozinaldo Antonio Miani, Universidade Estadual de Londrina, Brasil Sérgio Luiz Gadini, Universidade Estadual de Ponta Grossa, Brasil Simone Maria Andrade Pereira de Sá, Universidade Federal Fluminense, Brasil Veneza Mayora Ronsini, Universidade Federal de Santa Maria, Brasil Walmir Albuquerque Barbosa, Universidade Federal do Amazonas, Brasil

\section{COMISSÃO EDITORIAL}

\section{Cristiane Freitas Gutfreind}

Pontifícia Universidade Católica do Rio Grande do Sul, Brasil

\section{Irene Machado}

Universidade de São Paulo, Brasil

Jorge Cardoso Filho

Universidade Federal do Reconcavo da Bahia, Brasil

Universidade Federal da Bahia, Brasil

\section{EQUIPE TÉCNICA}

ASSISTENTE EDITORIAL I Márcio Zanetti Negrini

REVISÃO DE TEXTOS I Press Revisão

EDITORAÇÃO ELETRÔNICA I Roka Estúdio

CONTATO I revistaecompos@gmail.com
COMPóS I www.compos.org.br

Associação Nacional dos Programas de Pós-Graduação em Comunicação

Presidente

Edson Fernando Dalmonte

Programa de Pós-Graduação em Comunicação

e Cultura Contemporânea - UFBA

edsondalmonte@uol.com.br

Vice-presidente

Cristiane Freitas Gutfreind

Programa de Pós-Graduação em Comunicação Social - PUC-RS cristianefreitas@pucrs.br

Secretário-Geral

Rogério Ferraraz

Programa de Pós-Graduação em Comunicação

Universidade Anhembi Morumbi

rogerioferraraz@anhembimorumbi.edu.br 